\title{
El control de los patrimonios monásticos en la Galicia moderna
}

\author{
Pegerto SaAvedra
}

\begin{abstract}
PALABRAS CLAVE: monasterios gallegos, control de los patrimonios, foros, malicia campesina.
\end{abstract}

\section{CÓDIGOS JEL: Q15, N53, N83, N93.}

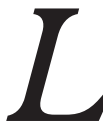

os monasterios benitos y bernardos, con una extraordinaria implantación en Galicia, fueron desde los siglos XII-XIII titulares de grandes dominios cedidos en foro

a los campesinos. La extensión, dispersión y fragmentación de los patrimonios, la circulación entre parientes y vecinos de las tierras aforadas y los cambios intensos que en el curso de la Edad Moderna notó el paisaje agrario favorecían las estrategias de los colonos orientadas a borrar las huellas del directo dominio, y obligaban a los religiosos a realizar un continuo esfuerzo para controlar explotaciones y parcelas y las cargas que pesaban sobre ellas, pues a la postre eran las rentas, y no las medidas de superficie, las que servían para estimar la entidad de los patrimonios.

A partir de la consulta de una abundante documentación, procedente sobre todo de los excelentes archivos de las comunidades cistercienses, este trabajo estudia los diversos mecanismos que los monasterios ensayaron en cada época para tratar de controlar sus tierras y rentas: primero los apeos, después el intento de convertir los foros en arriendos, y finalmente, como último recurso ya en la etapa final del Antiguo Régimen, los prorrateos. En apariencia, los monasterios gallegos tuvieron escaso éxito en sus esfuerzos, dada la poca eficacia de los apeos y la imposibilidad de acabar con las cesiones forales, pero las contabilidades ponen de manifiesto que llegaron a la desamortización y exclaustración cobrando la casi totalidad de sus rentas, lo que no puede decirse de otras comunidades religiosas de la Península. 


\section{Control of monastic properties in modern Galicia}

\section{KEYWORDS: galician monasteries, control of lands, foros, peasant resistance.}

\section{JEL CODES: Q15, N53, N83, N93.}

rom the twelfth century on significant numbers of Benedictine and Bernar-
dian monasteries in the region of Galicia owned great dominions that were
ceded under foral arrangements to peasants. These land colonizers implemented strategies of undermining direct dominion thanks to the fragmentation, dispersion and extension of the land, along with the fact that the right to cultivate land could pass to relatives or neighbours. Moreover, the intense changes affecting the agricultural land structure in the Modern Age forced the religious orders to continually seek to control these farm lands and to clarify the obligations of the tenants. Ultimately it was not the amount of land or the surface measurements that mattered for estimating the properties, but rather the land production or rents.

Mainly using the abundant documentation in the splendid Cistercian archives, this paper examines the various mechanisms that the monasteries employed in each period to seek to control their lands and rents. First were the attempts to define the delimitation of the lands (apeos). Next came efforts to transform foral land tenancy into leased land arrangements. Finally, in the last part of the Ancien Regime, prorating was used. Given the rather inefficient outcome of the delimitation of land and the failed attempts to end the foral arrangements, a cursory reading would suggest that the Galician monasteries were not very successful in their efforts. Yet their accounting indicates that they actually managed to collect almost the entire amount of their rents at the time of the disentailment and exclaustration of church lands, which is more than can be said of other religious communities throughout the Iberian Peninsula.

Recepción: 2016-09-08 - Revisión: 2017-02-27 - Aceptación: 2017-03-12

Pegerto Saavedra es catedrático de Historia Moderna en la Facultade de Xeografía e Historia de la Universidade de Santiago de Compostela. Dirección para correspondencia: Facultade de Xeografía e Historia, pza. Universidade, 1, 15782 Santiago de Compostela (España).C.e.:pegerto.saavedra@usc.es 
En memoria de Ángel García Sanz

\section{INTRODUCCIÓN: UNOS EXTENSOS PATRIMONIOS TERRITORIALES ESTIMADOS EN RENTAS}

El patrimonio arquitectónico, en particular el correspondiente al Barroco, y otro menos visible, caso del de carácter archivístico, constituyen pruebas patentes del enorme poder económico, social y también cultural que el clero regular y secular y las familias de la nobleza alcanzaron en la Galicia de la Edad Moderna. Como perceptor de rentas de variada naturaleza jurídica, el estamento eclesiástico aventajaba en riqueza a la hidalguía, y así lo proclaman las grandes fábricas monásticas y catedralicias, algunas casas priorales y desde luego las cerca de 3.800 iglesias parroquiales que salpican el territorio, al lado de las cuales los pazos, aun siendo muchos y algunos de bella traza, ocupan en el terreno de la arquitectura monumental el lugar de parientes pobres. La hegemonía de la Iglesia la acredita también, y de un modo más preciso, el catastro de Ensenada, toda vez que según los datos finales correspondientes a todo el reino, referidos al reparto de foros, diezmos, voto de Santiago y otros capítulos menores del excedente campesino, al primer estamento le correspondían al menos dos tercios, y a los legos, básicamente la nobleza cortesana y la hidalguía de pazo, el otro, o quizá algo menos. En efecto, foros, diezmos, voto y primicia y los llamados derechos de señorío se valoran en 1753 en 22,7 millones de reales, de los cuales unos quince pertenecían al clero secular y regular. Estas cifras no han de reputarse de exactas en lo que toca a sus valores absolutos, porque, debido a las múltiples ocultaciones del catastro de Ensenada, están infravaloradas, en especial las correspondientes al diezmo, afectado por los fraudes en las declaraciones de superficies, calidades y rendimientos, lo que a la postre, a la vista de que más del $90 \%$ de esa carga iba a la Iglesia, reduce de modo engañoso la ventaja de este estamento en el reparto del excedente global generado por los campesinos (Saavedra, 1990: 129).

El clero era, por tanto, muy poderoso, pero también muy heterogéneo internamente, no solo por la diversa cuantía de las rentas que percibían instituciones y personas, sino por la naturaleza jurídica de su procedencia. De modo sintético podemos indicar que los seculares, en particular los obispos, cabildos y colegiatas y los párrocos, tenían en los diezmos su fuente fundamental de ingresos. En cambio, los monasterios benitos y bernardos basaban en los foros el grueso de sus rentas, siendo secundarios -aunque no despreciables- los diezmos, e irrelevantes las cargas conceptuadas en la etapa final del Antiguo Régimen de derechos de señorío (Fernández González, 1998: 49-51; Rey, 1992: 149). Esto quiere decir que los monjes eran los principales titulares de extensos patrimonios territoriales, cedidos en foro desde la Baja Edad Media.Y al respecto conviene recordar que Galicia concentraba en su recinto numerosas comunidades monásticas, varias de ellas opu- 
lentas: 11 benitas y 14 cistercienses, de las cuales solo dos en el primer caso (San Paio de Santiago y A Guarda) y una en el segundo (Ferreira de Pantón) eran de monjas. En ellas residía en la segunda mitad del XviII, de acuerdo con los datos del censo de Floridablanca, una cuarta parte de los benitos y más de un tercio de los cistercienses de toda España.

En el caso de los cistercienses, de los que nos ocupamos básicamente en este trabajo debido a que sus archivos son más ricos que los pertenecientes a los benitos, disponemos de abundante información contable que acredita que Oseira y Sobrado estaban entre los más ricos de la llamada Congregación de la Observancia de Castilla, y que Meira, Melón, Monfero, Montederramo y Oia ocupaban asimismo un lugar decoroso, mientras A Franqueira o Penamaior no alcanzaban la condición de abadías y los gobernaba un presidente subordinado al abad de Palazuelos. En efecto, en la década de 1790 los dos primeros sostenían de 80 a 100 monjes, y sus ingresos financieros rondaban los 325.000 reales; los medianos con unas entradas monetarias de 100.000-150.000 reales, estaban habitados por 30-50 religiosos, mientras en A Franqueira vivían solo 5 monjes, que administraban 22.500 reales ${ }^{1}$.

En todo caso, las entradas en numerario, al proceder en su casi totalidad de la comercialización de cereales y vino cobrados, en teoría, en su propia especie (no pocas veces los colonos pagaban en dinero), sirven para establecer comparaciones entre comunidades y para conocer su situación financiera, pero no constituyen sus ingresos totales, pues entre una cuarta parte y un tercio de las rentas se destinaban al consumo de religiosos, criados, asalariados temporales, pobres y animales domésticos, y por lo mismo no se vendían. Significativamente, los patrimonios de los monasterios, y en general de las casas nobles, se evaluaban en rentas en especie, y no en medidas de superficie (no eran monasterios de labranza) y, salvo la cerca que rodeaba cada abadía y alguna huerta, prado o viña en los prioratos, las tierras y viviendas que componían los dominios las cultivaban campesinos foreros. En el catastro de Ensenada la condición de rentistas de las comunidades monásticas queda también patente: los bienes sobre los que ejercían el directo dominio los declaran los colonos, con indicación de las rentas que pagan por ellas, de ahí que en los resúmenes finales o mapas los eclesiásticos figuren como propietarios de menos del $10 \%$ de las tierras de Galicia, porcentaje que se corresponde con las que trabajaban por sí mismos o con criados, o que tenían cedidas en arriendo ${ }^{2}$.

1.Utilizamos para las cifras de ingresos los libros de estado y caja de los diversos monasterios del Archivo Histórico Nacional (AHN), para Armenteira, Oia y A Franqueira; Arquivo do Reino de Galicia (ARG), para Sobrado y Monfero; Arquivo Histórico Provincial de Ourense (AHPO), para Oseira, Montederramo, San Clodio y Xunqueira; y Arquivo Diocesano de Ourense, para Melón. El número de monjes figura en los mismos libros, y en el censo de Floridablanca.

2.GRUPO'75 (1977: 189-195), con los datos del reparto de la propiedad de la tierra en las provin- 
Disponemos, por lo mismo, de abundante información sobre el volumen de rentas y de mucha menos sobre la extensión de los patrimonios, y cuando ésta última existe suele ser parcial e imprecisa. Pero, a la vez, como los ingresos eran heterogéneos, resulta muy difícil hallar un índice que permita homogeneizarlos todos y compararlos. Las rentas del monasterio de Oseira, por ejemplo, ascendían en 1544 a unas 4.000 fanegas de pan (centeno, con cortas cantidades de trigo y mijo), 665 moyos de vino, 277 carneros, 451 capones, 94 gallinas, 159 puercos, 12 porcallas, 20 docenas de anguilas, cuatro carros de leña y paja y algunas libras de cera y manteca. En vísperas de la desamortización las entradas de pan rondaban las 7.250 fanegas y las de vino los 1.640 moyos, lo que junto con Sobrado, convertía a esta comunidad en una de las más opulentas de la Congregación de la Observancia de Castilla ${ }^{3}$. Las rentas de San Clodio consistían en 1608 en 618 fanegas de cereal (604 de ellas de centeno), 908 moyos de vino, 224 gallinas, 24 tocinos, 18 puercos, 25 porcallas, 32 carneros, un cabrito, 96 libras de cera, dos solomillos, dos carros de leña, un azumbre de manteca, un cuartillo de aceite, cuatro fanegas y media de castañas verdes y $4.475,5$ reales procedentes de foros en dinero, juros, laudemios y otras derechuras ${ }^{4}$. Las del monasterio de Oia, en 1616, estaban compuestas por 371,5 fanegas de trigo, 1.120,75 de centeno, 1.037,25 de mijo, 162 de cebada, 44 pipas de vino, 279 gallinas, 15 pollos, un pato, 72 carneros, 60 cabritos, 27 marranas, 15 pescadas, 22 lampreas, 23 sábalos, 21 libras de manteca, 96,5 de cera, 3,5 azumbres de miel, seis arrobas de aceite y una cantidad variable de reales derivados de luctuosas, laudemios, décimas y derecho de vasallaje ${ }^{5}$.Y por citar un último caso, el monasterio de Monfero cobraba a mediados del XVIII 150 fanegas de trigo, 2.110 de centeno, 415 de maíz, 140 de mijo, 60 de avenas, 80 pipas de vino, 200 carneros, 318 capones, 223 gallinas, 69 roxelos (ovejas y cabras), 23 tocinos, 300 cuartillos de manteca, 120 libras de cera, 829 carretos (prestaciones de los colonos-vasallos con bueyes y carro) y diversas entradas en numerario ${ }^{6}$.

Pero el hecho de que los patrimonios monásticos se estimasen siempre a partir del volumen de rentas que generaban, y no de la extensión que alcanzaban, no eximía a sus titulares de la necesidad de conocer y controlar las tierras por cuyo usufructo los cultivadores pagaban las correspondientes pensiones. Habría que decir que más bien les obligaba a ello. Al análisis de los mecanismos empleados para ese control está dedicado el presente trabajo.Y aunque la cuestión puede parecer en principio casi un lugar común, pues a fin

cias de la Corona de Castilla

3.Biblioteca del monasterio de Poio, libro de estado de Oseira. En sus contabilidades, los monasterios suelen emplear la fanega de Ávila (55,5 litros) y el moyo de 128 litros. La pipa tiene tres moyos.

4.AHN, Clero, cód. 424.

5.AHN, Clero, lib. 10.023.

6.ARG, Monasterios, Monfero, lib. 12. 
de cuentas en todas partes los "propietarios» se esforzaban por conservar sus patrimonios, en el caso de Galicia la habitual dispersión e interpolación de dominios en el espacio de una misma aldea y a menudo dentro de la misma explotación, los cambios en los tipos de cultivos y en general en la configuración del paisaje agrario, y la continua circulación y fragmentación de la tierra en el ámbito familiar y comunitario que el foro hacía posible -en la práctica- a través de transmisiones a varios herederos, compraventas, cesiones y trueques, dificultaban severamente el seguimiento por parte de los directos dominios de los avatares que a lo largo del tiempo notaban las parcelas y explotaciones que componían un dominio radicado en cientos de aldeas y parroquias (Pérez García, 1979: 164166; Villares, 1982: 23-25).

Este problema no ha pasado desapercibido a los estudiosos de la historia rural, pero, a lo que entendemos, nunca se ha analizado en la larga duración, atendiendo a los diferentes mecanismos que en cada época trataron de utilizar los rentistas: primero los apeos, después la transformación de los foros en arriendos, y finalmente los prorrateos. No basta con saber qué es un apeo; hay que explicar por qué este instrumento se revela poco eficiente para el control del territorio, lo que abre la puerta al intento de implantar los arriendos en vez de los foros $-\mathrm{y}$ arroja luz sobre la cronología de este proceso- $\mathrm{y}$, una vez que los monasterios ven cerrada esta vía, multiplican los prorrateos.Y todas estas cuestiones han de analizarse desde una perspectiva comparatista.

\section{EL RECURSO DE LOS DIRECTOS DOMINIOS A LOS APEOS}

Después de un largo y complicado proceso, en el que no faltó la violencia, culminado a mediados del XVI, los nueve monasterios masculinos benitos acabaron incorporados en la Congregación de San Benito de Valladolid, y los trece bernardos en la Congregación de la Observancia de Castilla, con lo que perdían su anterior independencia y debían regirse de acuerdo con las Constituciones o Definiciones inspiradas por una cúpula formada por el General, definidores y visitadores, y aprobadas en los capítulos que se celebraban -en el caso del Císter- en el monasterio de Palazuelos a principios de mayo de cada tres años o cuatro, cuando se renovaban los diversos cargos, entre ellos las abadías, trienales hasta 1759 y cuatrienales después. No corresponde ahora hacer una historia de la Congregación bernarda, en la que abundaron las tensiones de tipo territorial, con un destacado protagonismo de los monasterios gallegos, en especial en las tres primeras décadas del XviII (Martín, 1953:75-81). Sí conviene destacar que las Definiciones, cuyo esqueleto estaba diseñado hacia 1550, y otras disposiciones no solo fijaron las normas para llevar la contabilidad de casas centrales y prioratos, sino que obligaron a los monasterios a la creación de archivos en sentido estricto, y por tanto a la elaboración de libros tumbo o 
registro y resumen de los documentos conservados, y a la realización de apeos o inventarios judiciales del patrimonio (equivalentes a los terriers franceses, a los capbreus de los territorios de lengua catalana y a los tombos portugueses), y a la consiguiente presentación de demandas de «reivindicación», para que los posesores de bienes forales reconociesen el directo dominio y pagasen las correspondientes rentas.

Tal es la razón por la que, aunque los hay antes y después, los tumbos y apeos se concentran sobre todo en el siglo que va de 1560 a 1660, y de modo especial en las dos últimas décadas del XVI y tres primeras del XVII. De los 104 apeos conservados en los fondos de la Real Audiencia, 64 se realizaron entre 1570 y 1609; de la segunda mitad del XVII solo hay 12 y del xviII, 4 redactados entre 1717 y 1732 (Quiroga, 1999) Del archivo del monasterio de Melón se conocen 25 apeos, 21 de ellos correspondientes al período de 1560 a 1660, y en lo que toca a Oseira, en ese mismo siglo se sitúan 28 de $33^{7}$. Por otro lado, los libros tumbo o inventarios de todas las escrituras conservadas, que se resumen o incluso se copian verbo ad verbum si se consideran muy importantes, se elaboraron en los últimos años del siglo XVI y en la primera mitad del XVII cuando se crean como tales los archivos monásticos. En Montederramo, Meira, Oia, San Clodio y Oseira la reordenación archivística tiene lugar en 1610-1630, pero se trata sin duda de un movimiento general entre cistercienses y benitos, como sabemos por los datos referidos a las poderosas comunidades de Celanova y San Martiño Pinario ${ }^{8}$.

En una época en la que el gobierno de la monarquía y de los estados señoriales se había burocratizado, estaba en manos de letrados y el derecho ocupaba un lugar central para resolver conflictos de todo tipo, en particular los patrimoniales, los archivos adquirían una importancia decisiva en todo lo que tocaba a la propiedad y posesión. La antigua observancia o posesión inmemorial constituía también en la jurisprudencia castellana prueba con el valor de un documento, pero los monasterios y en general los señores no encontraban en ocasiones campesinos que estuviesen dispuestos a declarar a su favor. Como decía en 1606 fray Martín Ordóñez, encargado de organizar los archivos de Armenteira y Oia, en su origen los monasterios se beneficiaron de generosas donaciones reales,

7.Ferro (1980). Podrían añadirse más ejemplos: los 35 apeos del monasterio de San Martín Pinario conservados en el Archivo Histórico de la Universidad de Santiago se realizaron entre 1550 y 1624; y seis de los siete de Poio del AHN en la segunda mitad del XVI.

8.Lucas (1999); Gallego (1991); Quiroga (1986); Portela, Garrido y Romaní (1993). Repertorios y tumbos ponen de manifiesto que el criterio topográfico era común para la organización de un archivo; la documentación de un priorato se guardaba, por ejemplo, en unos determinados cajones, para su fácil localización. 
pero ahora, por nuestros pecados, todos o los más tratan de despojarnos y llevarnos lo que con tan larga mano los fundadores nos dexaron, y ha venido a tanta miseria este negadio que buscando las armas con que nos defender y mostrar nuestro derecho y justicia, que son las donaciones, privilegios y otras escrituras antiguas, no se hallan.

Y cuando se conservan apenas pueden leerse debido a su deterioro, causado por la humedad, por los ratones o por la reutilización, cosa lastimosa, pues los documentos son la luz y fuerza y estado para la conservación de lo ganado y para la defensa y amparo y probanza de lo perdido ${ }^{9}$.Y, en efecto, la revisión y clasificación de las escrituras existentes convenció a los monjes de que las comunidades habían perdido mucho patrimonio. Los lamentos al respecto menudean en los libros tumbo, caso del de Melón (mucha hacienda tenía este monasterio[...]; se ha perdido gran parte della[...] y cada día se va perdiendo más $)^{10}$.

Los tumbos eran trabajosos porque requerían agrupar o cruzar los documentos referidos a una misma parcela o explotación, y concordarlos. De hecho, tales instrumentos los realizaban monjes expertos que iban de un monasterio a otro, conscientes de que el resultado de su labor constituía el instrumento fundamental del archivo y a la vez renovaba la memoria de la institución, al incluir la historia (fundación, privilegios reales, bulas, abadologio) de un pasado glorioso. Así, el autor del de Sobrado declara al comienzo que no es razón que las cosas notables queden sepultadas en la noche del olvido, sino que perseveren en el conocimiento de los hombres, y más cuando se trata de un monasterio que «en religión, $y$ sanctidad, $y$ culto divino, $y$ aun en lo que es menos, en grandeza de edificios, antigüedad, sitio y riquezas", puede contarse entre los primeros de toda Europa: Renovemos las memorias que a nosotros han venido, conservadas con la diligencia y cuidado de nuestros pasados en los archivos..., proclama el celoso monje ${ }^{11}$.

Pero los apeos eran más laboriosos y conflictivos, pues una vez concedida la autorización de la justicia, a menudo la Real Audiencia, los monjes debían contar con la colaboración de campesinos dispuestos a identificar las tierras y reconocer el dominio monástico sobre ellas. El archivero del monasterio de San Clodio manifestaba en 1616 su exasperación e impotencia ante la mala disposición de los colonos:

9.AHN, Clero, lib. 10.323.

10.AHPO, Clero, lib. 399, con más anotaciones del mismo tenor.

11.AHN, Clero, cód. 341. Sobre este tumbo en concreto, véase SuÁrEZ GoNZÁlEZ (2016). 
en esta tierra he hallado por experiencia hay mucha facilidad en negar la hacienda que es del monasterio, haciéndola diezmo a Dios, y dado caso de que no lo hagan, muchas veces no pagan bien (...). Y ansi hay grandísima necesidad de poner remedio en esto, y no sé cual pueda ser.

Convenía, a la hora de realizar apeos, tener algunos paniaguados en cada granja, para que puedan dar luz, porque esto en ninguna manera se puede hacer por especulación, y en última instancia informar a los letrados de la Audiencia, para que amparasen al monasterio:

$Y$ ansí, si se hubiesen de seguir algunos pleitos será bien hablar aquello [a los] señores oidores e informarles de lo que pasa», pues «no es razón que ahora [el monasterio] la pierda por maliçia de los que la quieren negar, por no hallar testigos que lo digan, que si en un lugar hay treinta vecinos y los veinte y nueve quieren ocultar cada uno la parte que lleva mal se podrá hacer probanza en favor del monasterio» ${ }^{12}$.

La realización de un apeo, habida cuenta de la falta de colaboración de muchos colonos a la hora de reconocer el dominio monástico, exigía la presencia sobre el terreno, acompañando al receptor de la Real Audiencia o a otro oficial de la justicia, de un monje buen conocedor del archivo, capaz de exhibir en cada caso las escrituras que acreditaban el directo dominio. Si la comunidad se descuidaba en esto, el remedio podía resultar peor que la enfermedad, como afirmaba un religioso de Penamaior a propósito de un apeo de 1650, que diera ocasión al extravío o robo de muchos documentos:

de haberse hecho el dicho apeo se siguió al monasterio más daño que provecho [porque, además de la pérdida de papeles] como en esta tierra son tantas las ventas que los caseros haçen de pan de renta cada día a diversas personas, como ellos mismos fueron testigos y vedraños que, como poseedores de los bienes del monasterio declararon en dicho apeo, declaraban lo que querían y callaban lo demás [...], por esta causa había muchos bienes perdidos y enajenados, de que no se cobraba renta alguna ${ }^{13}$.

12.AHN, Clero, cód. 424 .

13.AHN, Clero, lib. 6.207. Se refiere el monje a ventas de rentas aseguradas sobre bienes del directo dominio del monasterio, sin dar noticia a éste, o ventas incluso de tierras aforadas como si fueran alodiales del forero. 
Con todo, superando enormes dificultades, los fondos archivísticos acreditan que los monjes consiguieron realizar cientos de apeos, algunos extraordinariamente voluminosos, en los que las parcelas se describen de modo elemental, indicando el sitio -con su topónimo- en donde radican, su extensión aproximada-poco más o menos- en ferrados, la dedicación y las confrontaciones o límites, que se especifican atendiendo principalmente al nombre del posesor de las parcelas colindantes, lo que a la larga traía complicaciones, pues las personas desaparecían, y con ellas las referencias para identificar una tierra (Saavedra, 2013: 74-76).

\section{UNOS PATRIMONIOS DESCRITOS, PERO NO CARTOGRAFIADOS}

Miles y miles de folios escribieron los pendolistas que acompañaban a los receptores, corregidores o jueces ordinarios encargados de la realización de apeos y que transcribían, traduciéndolas al castellano, las declaraciones de los testigos. Sin embargo, en ese océano paleográfico resulta insólito encontrar planos o mapas que representen los bienes descritos. Todo se reduce a un río de párrafos que reproducen lo que dijeron los vecinos o comarcanos de los bienes apeados. En principio, esto no deja de sorprender, pues en diversos territorios europeos los terriers van acompañados de plans, o los estate de maps, esto es, de un aparato cartográfico que representa un dominio o parte de él. En el caso de Francia, en su momento ya el gran Marc Bloch llamó la atención sobre el interés de los plans terriers para el conocimiento de la organización del territorio y en general del paisaje agrario, y más recientemente han sido objeto de estudio por diversos ruralistas, y de modo muy especial por Annie Antoine. También se conocen bellos ejemplos de los Países Bajos, fechados en el tránsito del XVI al XVII, y planos de poderi de la Italia central y nórdica cedidos en aparcería (mezzadria) ${ }^{14}$.

Con todo, en el terreno de la cartografía agraria ningún país sostiene una comparación con Inglaterra, en donde a partir de 1570-1580 comienzan a abundar los estate maps, con una información precisa y visual, que no proporcionaban los apeos tradicionales que se limitaban a describir y medir las propiedades, los únicos que se hicieron en Galicia en toda la Edad Moderna. Los avances científicos, ligados a la difusión del puritanismo, que reforzaban las ideas de innovación y progreso, fueron asumidos también por muchos grandes propietarios, deseosos de mejorar, tanto los métodos de gestión como las técnicas de cultivo, lo que suponía una renovación de la ideología del improvement, aplicada a unos

14.ANTOINE (2001); BlOCH (1929); considera que los terriers con cartografía precisa son escasos antes de 1740; Brunel, GuyotjEanNin y Moriceau (2002); sobre Italia, SERENi (1961); también Congost, Jover y BiAgIOLI (2003). 
patrimonios en los que los derechos de propiedad aparecían cada vez más clarificados. En este contexto, la elaboración de estate maps constituía una prueba de que el propietario era un conocido defensor de la introducción de esas mejoras, así en los sistemas de cultivo como en la gestión. Surgió entonces un numeroso y cualificado grupo socioprofesional de land surveyors, dedicado a la elaboración de estate maps y en ocasiones a la redacción de manuales sobre improvement y a la tasación de tierras en operaciones de compraventa (Beauroy, 2002; McRae, 2002; Bendall, 2010).

Pues bien, entre los miles de páginas de los apeos de los monasterios de Galicia, y de otras instituciones eclesiásticas y familias rentistas, no encontramos representaciones cartográficas que los aproximen, no ya a los estate maps ingleses, sino a los plans terriers franceses. La falta de un cuerpo de agrimensores y a la vez el hecho de que los apeos no estén orientados a cambios en las formas de gestión, sino a garantizar el derecho del directo dominio sobre tierras aforadas a campesinos que las cultivaban sin intervención o dirección alguna de los rentistas, explican en buena medida la ausencia de cartografía.

Pero al margen de la falta de un cuerpo de agrimensores, que podrían buscarse fuera de Galicia o sustituirlos por cartógrafos militares, y de la vigencia de unas formas de gestión patrimonial que buscaban la obtención de unas rentas en especie a menudo de tipo fijo y estabilizadas durante generaciones, había otro factor que desaconsejaba abordar la laboriosa y costosa tarea de levantamiento de planos y mapas. Y es que estos instrumentos de control -y prestigio, colgados en los gabinetes- eran útiles cuando su vigencia se mantenía largo tiempo, debido a que el paisaje cambiaba poco. En buena parte de Galicia durante la Edad Moderna ocurrió lo contrario: la fuerte expansión demográfica y el aumento de la superficie cultivada, las transformaciones en los tipos de cultivos, la parcelación del terrazgo por los repartos hereditarios, la circulación de la tierra por obra de trueques y compraventas... Todos estos factores volvían anticuado un apeo en el discurso de pocos años, y lo mismo les ocurriría a los mapas, de haberse fabricado: pasado un breve tiempo el paisaje que allí se pintaba ya no existía.

Con esta realidad se toparon también los encargados de realizar el catastro de Ensenada, que en principio deberían ser auxiliados por agrimensores profesionales. Como no existían, hubieron de valerse, para el trabajo de peritos, de simples labradores de buen ojo, a menudo analfabetos, que efectuaban las mediciones y tasas de las partijas de los campesinos. Por ello, la Única incluye una escasa y tosca cartografía, al revés de lo que acontece con los catastros saboyano y milanés (Camarero, 1998; Touzery, 2007). Pero a los comisionados que actuaron en Galicia, exasperados por la parcelación del terrazgo -verdadera confusión de Babel-, les parecía incluso inútil describir y dibujar tanta infinitud de retacillos minutísimos, porque, además de tarea hercúlea, resultaba ineficaz, pues al poco 
tiempo las minúsculas parcelas no podían identificarse: en Galicia no hay configuración permanente ni aun de los caminos, que cada año la mudan sus dueños, vallan, desvallan, acortan y ensanchan sus tierras como les parece, de modo que el terrazgo de las aldeas se compone de millones de figuras voluntarias y cada año transeúntes ${ }^{15}$.

Desde mucho antes del catastro de Ensenada (llamado también a veces apeo), los monjes encargados de los archivos y de la realización de apeos venían denunciando la fragmentación, la circulación de las parcelas de una explotación y los consiguientes procesos de oscurecimiento del directo dominio sobre ellas. Las escrituras de foro autorizaban la transmisión hereditaria de los bienes, pero a menudo a un único heredero, que debía comparecer ante los monjes para ser reconocido como voz o cabeza de foro; también se permitían las ventas del dominio útil, dando noticia previa al monasterio por si quería ejercer el derecho de tanteo y en todo caso para cobrar la décima o laudemio. No faltan en los archivos libros de nombramientos de voces, ni de ingresos por laudemios, pero las prácticas campesinas a menudo no respetaban las normas escritas: los bienes forales se transmitían según la usanza de cada comarca, desde la mejora larga que beneficiaba a un único heredero hasta la partición igualitaria, y se trocaban, hipotecaban, subforaban, vendían, se integraban en mayorazgos y obras pías....

De todos estos problemas dieron cumplida razón religiosos cuya brega continua con campesinos taimados les autorizaba a dejar por escrito advertencias para que sus compañeros o sucesores no pecasen de ingenuos. Uno de Oia señalaba hacia 1700 que eran varias las mañas de los colonos para oscurecer el dominio del monasterio, pero entre las más principales estaban los enredos de las partijas: aunque las familias poseyesen bienes de varios dominios -algo habitual-, a la muerte del cabeza de casa hacen sus herederos un montón de todos ellos, como cosa suya, y luego los parten. A continuación hacían lo propio con las rentas y pensiones, pero sin procurar -más bien lo contrario- que cada heredero pagase al señor del directo de los bienes que le cupieran, lo que en caso de demandas por impagos o por otros motivos embarullaba el litigio, pues los campesinos afectados argüían que no cultivaban tierras del rentista que les citaba ante la justicia.Y la operación se repetía a cada generación:

Lo mesmo hacen otra vez los hïos destos, y después sus nietos, por muerte de cada petrucio, con que en largo tiempo todo es enredo, confusión y reboltorio

15.AGS, Dirección General de Rentas, $1{ }^{a}$ R., legs. 1.874 y 1.875, con abundantes quejas de los comisionados. Para las operaciones del catastro, véase SAAVEDRA (2007). 
para confusión de los bienes, que es lo que los labradores quieren, para que a río revuelto ganancia de pescadores ${ }^{16}$.

\section{EL INTENTO FRUSTRADO DE CONVERTIR LOS FOROS EN ARRIENDOS.}

La cronología de los libros de apeos pone de manifiesto que desde 1660-1680 los monasterios, y en general las familias e instituciones rentistas, desistieron de continuar renovándolos o actualizándolos, de ahí que sean tan escasos en el siglo XVIII, en comparación con el que va de 1560 a 1660 . Es más, no pocos legajos de 1750-1834 rotulados como apeos son en realidad prorrateos. El hecho de que tales instrumentos, en principio piezas fundamentales como pruebas de dominio al realizarse bajo control de la justicia (que acreditaba que su contenido había sido admitido públicamente por las comunidades vecinales), quedasen pronto envejecidos y por lo mismo de valor dudoso en los pleitos, constituye en nuestra opinión la causa principal de su casi desaparición. A mayores, la creciente parcelación del terrazgo y el incremento del número de cultivadores de las tierras cedidas en origen a una sola familia dificultaban y encarecían con el paso del tiempo la elaboración de esos inventarios judiciales.

En todo caso, la renuncia de los directos dominios de Galicia a los apeos como medio de control de los patrimonios no deja de llamar la atención del investigador, pues ni en Francia, ni en Portugal, ni en los territorios de la Corona de Aragón, por ejemplo, sucedió algo parecido. Sin duda hay que tener en cuenta para explicar estos contrastes que el foro era una cesión temporal, aunque de larga duración, y en consecuencia los directos dominios disponían en principio de la posibilidad de recuperar la propiedad plena de las tierras, lo que no sucedía con la enfiteusis perpetua de Cataluña, Valencia o Francia, salvo impago de las pensiones. En estas situaciones, los señores debían obligar periódicamente al propietario del útil a reconocer el dominio mayor que afectaba a sus bienes, con las cargas correspondientes. $Y$ a tal efecto los terriers, tombos y capbreus resultaban imprescindibles. Así, aún a fines del Antiguo Régimen alcanzó notable difusión la obra del jurista barcelonés Jaume Tos i Urgellès, Tratado de la cabrevación según el derecho y estilo del Principado de Cataluña, aparecida en 1784, de la que la profesora Rosa Congost ha realizado una valiosa edición en 2007. En el caso de Francia es también en el XVIII cuando se elaboran los plans terriers más ricos en información, en especial la de tipo cartográfico ${ }^{17}$.

16.AHN, Clero, cód. 60, con todas citas documentales referidas a Oia. Otra advertencia parecida en los fondos de Penamaior, lib. 6.207.

17.Tos I URGELLÉS (2007); en 1788 escribió una adición a esta obra. Para el caso de los terriers fran- 
$\mathrm{Al}$ desistir de la realización de apeos, los monasterios gallegos optaron por otras formas de control del dominio y de la cobranza de rentas. Redactaron con más precisión, a la hora de describir las parcelas, las escrituras de foro; confeccionaron gruesos libros cobradores de prioratos, panera, bodega y verbos, en los que quedaba identificado nominalmente cada colono con las cargas que debía pagar al año; nombraron cabezaleros o responsables de reunir la renta de cada foral, y sobre todo, y en este punto nos detendremos a continuación, trataron de convertir los foros en arriendos y, cuando tal propósito no pudo llevarse a término, generalizaron la práctica de prorrateos o redistribución de las rentas conforme las tierras que las pagaban cambiaban de cultivador debido a su intensa circulación $^{18}$.

Como quedó indicado, a diferencia de la enfiteusis, el foro era efectivamente un contrato temporal, que hasta avanzado el siglo XVII se estipulaba por voces o generaciones, a menudo tres. En teoría, conocer el momento de la caducidad de la cesión no parece complicado, pues ésta vendría determinada por el fallecimiento del nieto o nieta de los tomadores del foro (cuando era un matrimonio, la primera voz acaba al morir el cónyuge sobreviviente). En la práctica, sin embargo, las cosas eran más complejas, por cuanto aparte de las dudas que surgían cuando a falta de sucesión directa los parientes herederos continuaban como voz, los colonos trataban de ocultar muertes, alargando así la duración de los contratos, y, además, al dividir los bienes resultaba dificultoso identificar la voz principal. En principio, a la muerte de un cabeza de foro, el heredero debía comparecer en el monasterio para ser reconocido como voz siguiente, y por ello se conservan algunos libros de nombramientos de voces, pero esta obligación distaba de cumplirse: hay grandísima necesidad de nombrar voces, porque si no los colonos quieren hacer los foros perpetuos, y aunque vaquen no hacen caso de hacer foro nuevo, sino llevarlo como se les antoja, decía en 1608 el archivero de San Clodio ${ }^{19}$.

El control de la duración de un foro por voces exigía a los directos dominios seguir las diversas historias familiares, algo de por sí dificultoso en patrimonios muy dispersos, y más cuando a cada generación las tierras se fragmentaban. Un cambio importante, documentado ya en foros de la primera mitad del XVII, consistió en estipular la duración de las cesiones por vida de tres reyes de España, lo que facilitaba mucho la capacidad de comprobación de los directos dominios, pues, según esta cláusula, todos los foros otorgados en vida de Felipe III (1598-1621), por ejemplo, vacaron al morir su nieto Carlos II en sep-

ceses, véase ANTOINE (2001).

18.La serie más completa de libros cobradores que conocemos es la correspondiente al monasterio de Oia, tanto de la casa central como de los prioratos, AHN, Clero, fondo de Oia.

19.AHN, Clero, cód. 424. 
tiembre de 1700, y en 1746 y 1759 ocurrió lo mismo con los otorgados, respectivamente, en tiempos de Felipe IV y Carlos II. De este modo, al óbito de un rey, a los monasterios les bastaba con abrir los libros de foros para saber cuáles estaban finalizados, si bien en el XVIII continuaban en vigor cesiones por voces (Saavedra, 1985: 424).

Pero la duración por vida de reyes no evitaba que los colonos continuasen, en la práctica, disponiendo de la tierra a su albedrío, y por ello entre los monjes se difunde a fines del XVII, para generalizarse en la primera mitad del XVIII, la convicción de que para garantizar un control efectivo solo cabía despojar a los campesinos de los derechos de la propiedad útil que les otorgaba el foro, mediante su transformación en arrendatarios. El prior de Bóveda de Amoeiro, sufragáneo de San Martiño Pinario, explicaba con claridad el problema en 1742:

soy de sentir en Dios y en mi conciencia que si vacasen algunos foros no se vuelvan a aforar, sino ponerlos en arriendos; con esto reditúa más la hacienda, están más sujetos los caseros, no se pierden las haciendas, no hay pleitos sobre ellas [...], porque como se les puede quitar al acabar los arriendos [...] son más atentos y están más sujetos (Fernández González, 1995: 140).

No era una opinión particular, ya que los propios oidores de la Real Audiencia del Reino, que conocían bien el asunto, al substanciar los pleitos originados por la caducidad de los foros, en informe de 1768 sobre los prioratos de los bernardos manifestaban no albergar dudas de que

dicha religión [del Císter] no renovará los actuales foros de llegado el caso de su vacante, ni hará otros de nuevo en sus haciendas, por haberlo asi dispuesto en una de sus congregaciones generales, celebrada por los años pasados, en la que mandó que en lugar de foros se den en arrendamiento a labradores las haciendas de los monasterios ${ }^{20}$.

En las actas de los capítulos de las congregaciones y en los mandatos de los visitadores se encuentran, desde la segunda mitad del XVII, referencias a la conveniencia de arrendar en lugar de aforar ${ }^{21}$, pero habida cuenta de la duración de los foros los monjes debieron esperar a la muerte de Carlos II, Felipe V y Fernando VI para intentarlo, lo que explica que los conflictos por despojos se intensifiquen notablemente en 1700, 1746 y

20.Boletín de la Real Academia Gallega, Documentos Históricos (1906, vol. 1: 159).

21.Díaz-CASTROVERde (1992, vol. II: 405) da noticia de mandatos orientados a hacer arriendos en vez de foros (en el monasterio de Sobrado en 1675, 1712, 1731, 1745 y 1757). 
1759, por tanto, décadas después de que los religiosos experimentasen la ineficacia de los apeos para controlar los dominios y decidieran acudir a procedimientos más expeditivos. De hecho, en la Galicia cantábrica desde fines de 1670-1680 monasterios y conventos iniciaron, con cierto éxito, la conversión de foros en arriendos, cosa que no tuvo lugar en el resto de Galicia. No estamos en condiciones de explicar cabalmente esta diferencia, aunque cabe recordar que en el norte de las provincias de Mondoñedo y Betanzos la nobleza practicaba el arriendo de antiguo, y sin duda sirvió de ejemplo (Saavedra, 1985: 398-412).

La amenaza de verse convertidos en simples arrendatarios enconó la resistencia de los colonos a la hora de permitir que los monasterios recuperasen y dispusiesen de las tierras al vacar los foros, algo que el derecho les permitía, con independencia de que debiesen o no abonar mejoras ${ }^{22}$. Porque no es precisamente en el siglo XVIII cuando los cenobios presentan en la Real Audiencia una mayor cantidad de demandas de reivindicación o de recuperación de bienes aforados. El grueso de tales expedientes se concentra sobre todo en 1560-1639, cuando, a raíz de la elaboración de apeos y tumbos y la puesta en orden de los archivos, los monjes deciden obligar a los colonos a reconocer explícitamente el directo dominio de las tierras que cultivaban. Los datos del cuadro que sigue son al respecto bien resolutivos:

\section{CUADRO 1}

Evolución del número de demandas entabladas ante la Real Audiencia por todos los monasterios de Galicia, y porcentaje que suponen las de reivindicación de bienes entre las presentadas por ocho comunidades cistercienses

\begin{tabular}{lcrcrrrr}
\hline Años & $\begin{array}{c}\text { Demandas de todos } \\
\text { los monasterios }\end{array}$ & $\begin{array}{c}\text { Media } \\
\text { anual }\end{array}$ & $\begin{array}{c}\text { De ocho cenobios } \\
\text { cistercienses }\end{array}$ & $\begin{array}{r}\text { Media } \\
\text { anual }\end{array}$ & $\begin{array}{c}\text { De } \\
\text { reivindicación }\end{array}$ & $\begin{array}{c}\text { Media } \\
\text { anual }\end{array}$ & $\begin{array}{c}\% \\
\text { reivindicación }\end{array}$ \\
\hline $1560-1639$ & 4.576 & 52,7 & 1.744 & 21,8 & 1.570 & 19,6 & $90,-$ \\
$1640-1719$ & 2.188 & 27,4 & 762 & 9,5 & 539 & 6,7 & 70,7 \\
$1720-59$ & 503 & 12,6 & 165 & 4,1 & 89 & 2,2 & 53,9 \\
$1760-1834$ & 591 & 8,3 & 163 & 2,3 & 16 & 0,2 & 9,8 \\
\hline Total & $\mathbf{7 . 8 5 8}$ & $\mathbf{2 9 , -}$ & $\mathbf{2 . 8 3 4}$ & $\mathbf{1 0 , 5}$ & $\mathbf{2 . 2 1 4}$ & $\mathbf{8 , 2}$ & $\mathbf{7 8 , 1}$ \\
\hline
\end{tabular}

Fuente: elaboración a partir de Quiroga (2007).

Las cifras parecen tan elocuentes que no precisarían de mayores comentarios, ya que resulta patente el acusado descenso del número de demandas de reivindicación desde la primera mitad del XVII, y sobre todo desde 1700-1719.Y sin embargo, los expedientes tramitados en el segundo tercio del XVIII dieron origen a una conflictividad mucho más intensa 
que los de la segunda mitad del XVI y del XVII, muy abundantes. Las razones de este cambio están, a nuestro juicio, en que cuando la duración de los foros estaba fijada en voces, cada demanda afectaba a una familia, de acuerdo con su particular historia; en el XviII, al cumplirse los plazos de los foros estipulados por vida de reyes, al fallecimiento de Carlos II y sobre todo de Felipe V y Fernando VI, vacaban de repente cientos o miles de contratos, que los monasterios incluían en una o pocas demandas para ahorrar dispendios. En consecuencia, muchos foreros se veían al mismo tiempo afectados por un expediente de caducidad, y las posibilidades de organizar una resistencia colectiva se multiplicaban.

Además, a lo anterior se sumaba el que la subdivisión del terrazgo por repartos hereditarios y compraventas motivaba que las tierras de un foral acabaran en manos de docenas de personas, como ponen de relieve los libros cobradores de algunos monasterios del litoral occidental, en los que figuran cientos de campesinos pagando cantidades de cereal que se miden en concas $(1,33 \text { litros })^{23}$. Es decir, que el número de demandas a que se refiere el cuadro tiene poco que ver con el de demandados: más de 400 comprendidos en una del monasterio de Sobrado que afectaba a colonos del contorno; 391 en otra de Melón contra foreros de Rubillón y de varias feligresías del Ribeiro; 210 en otra del monasterio de Celanova..., todas ellas de mediados del xviII (Díaz-Castroverde, 1995:148-145). A mayores, las demandas de los siglos XVI y XVII tenían ante todo la finalidad de que los colonos reconociesen el directo dominio, para recibir a continuación nuevos foros; pero en el XVIII esta especie de trámite dio paso al novedoso propósito de los monasterios de convertir los foros en arriendos. Y a todo lo anterior se añadía el que en la década de 1750 los campesinos estaban informados, por abogados, clérigos o emigrantes retornados de la corte, que en los consejos de la monarquía, caso de los de Castilla y Estado, no existían demasiadas simpatías por el clero regular (los frailes no tienen patria, diría Grimaldi). Por último, la política agraria de los reformistas se orientaba, como bien señaló Ángel García Sanz (1996: 175-180), a favorecer la estabilidad de los cultivadores, y Campomanes en concreto escribía, cuando tenía entre sus manos el expediente sobre los foros, que las excesivas rentas que pagaban los campesinos gallegos estaban entre las causas de la emigración a Portugal (Luna, 2005).

Una corriente historiográfica entiende que la polémica que tiene lugar principalmente en el segundo tercio del XVIII por la renovación de foros es ante todo una contienda entre los monasterios benitos y bernardos y los hidalgos «intermediarios», herederos de parien-

23.La documentación del monasterio de Armenteira, en las Rías Baixas, ofrece numerosos ejemplos tanto de demandas de reivindicación con muchos cultivadores de pequeñas parcelas afectados como de la enorme fragmentación de los forales y de sus rentas. AHN, Clero, libs. 9.928 (demandas) y 9.975 (memoriales cobradores). 
tes agraciados con extensos forales cuyas tierras a su vez subforaran a campesinos, mientras los cultivadores permanecían al margen de la pugna, pero la documentación judicial desmiente tal hipótesis ${ }^{24}$. Es cierto que los hidalgos se opusieron a las pretensiones de los monasterios, utilizando las instituciones que controlaban, y encargaron diversos informes, siendo el más difundido La Natural Razón, editado en 1767, cuyo contenido se acomodaba al sentir regalista de Campomanes y de otros miembros de los consejos. En él la hidalguía reconoce paladinamente que son pocas las familias nobles que no perciban rentas de tierras subforadas, y que los despojos las dejarían en muchos casos en la ruina, pues muchos bienes forales o las rentas que generaban acabaran incorporadas a mayorazgos por los fundadores de casas nobles, lo que no se ajustaba a derecho, pues suponía que bienes de usufructo temporal se incluían en fundaciones establecidas para siempre jamás. Pero en este punto las prácticas de hidalgos y campesinos tenían poco que ver con las normas, de ahí el constante trasiego de tierras, que dificultaba la resolución de los pleitos de despojos: Preciso es también que sean difíciles los pleitos, especialmente en foros antiguos, afirma La Natural Razón. Después de múltiples partijas, compraventas, trueques, incorporaciones a vínculos y obras pías y otro tipo de incidencias: al cabo de dos o tres siglos, ¿dónde estarán esos bienes, después de tantas transmigraciones y partijas? Recurrir a los papeles es en vano (Villares \& Díaz Castroverde, 1997: 249).

A los monjes les resultaba incomprensible y violento que, vacados los foros, no pudiesen recuperar los bienes y realizar contratos nuevos, fuesen foros o arriendos, como habían venido haciendo hasta mediados del XVIII, apoyados en la jurisprudencia de la Real Audiencia. Ahora el problema no era de tan fácil resolución como pensaban los religiosos, pero solos los hidalgos no habrían podido frenar la ofensiva de los monasterios, pues sabemos de casos en que éstos, después de notables dispendios, vencieron en los tribunales y recuperaron bienes que llevaban generaciones en manos de familias poderosas. Así, Sobrado se posesionó en 1714-1720, tras ruidoso pleito, de la granja de Loureda, en la que los Tovar Maldonado alzaran una ostentosa "torre», y Oseira también despojó en la década de 1770 a la condesa de Fefiñáns y al marqués de Figueroa de la granja de la $\mathrm{Cu}-$ queira, después de un litigio que duró más de veinte años ante la Chancillería de Valladolid y la sala de Mil y Quinientas. La prueba de que el monasterio pleiteó con el mayor empeño está en que entre 1755-1756 y 1781-1782, cuando se encuaderna con todo lujo la ejecutoria ganada y se envía desde Madrid a Oseira como un tesoro, gastó unos 172.000 reales, entre los que se incluyeron 18.150 en regalos (66 docenas de jamones, 37 de barriles de escabeche, así como dulces, chocolate, tabaco y lienzos finos $)^{25}$.

24.Como demostraron en su momento Villares (1989; 1997) y Díaz-Castroverde (1992), frente a las hipótesis expresadas por BARREIRo (1972) y PÉREZ GARCía (1979).

25.AHPO, Clero, lib. 607 de Oseira con la relación anual de gastos en pleitos. 
La oposición a las demandas de los monasterios está protagonizada en diversos casos por algunos hidalgos y clérigos y por muchos más colonos, y la resistencia campesina, si era de tipo colectivo y territorialmente difundida, resultaba más difícil de vencer para los monasterios, entre otras razones porque los pleitos «ruidosos» podían dejar en mal lugar a instituciones que se presumían caritativas y tampoco resultaban gratos a los tribunales. Lo sabían bien los monjes de Oia cuando, enfrentados a los vecinos de cuatro parroquias en la década de 1730, optaron por interponer varias demandas, en vez de una sola contra todos:

por haberse consultado con los mejores abogados de España, los cuales dijeron que no convenía se dijera que se levantaba toda la jurisdicción, que sonaba esto muy mal en todos los tribunales, y que vencidas las dos feligresías se vencerían las otras dos [...] Referir por extenso -añade el archivero- los lances principales que se sucedieron por espacio de doce años que duró el principal litigio fuera llenar todo este tumbo y quedar a los principios del pleito. Cuatro veces fueron tumultuariamente los vecinos de estas dos parroquias a Madrid, delante de su Magestad. De la primera fueron hombres y mujeres más de noventa personas.

La victoria del monasterio no pacificó la situación, pues en 1751 intentó convertir en arriendos los foros de la feligresía de Loureza, pero pronto desistió:

para evitar que se levantasen a mayores, como habian hecho antes, $y$ todos se conjuraron en no admitirlo en arriendo, determinando marchar todos a Madrid con hijos y mujeres a quejarse al rey; el monasterio para evitar estas quexas ruidosas les volvió a hacer nuevo foro ${ }^{26}$.

Tampoco quisieron recibir arriendos en vez de foros unos cuatrocientos colonos de las inmediaciones de Sobrado, ni los vecinos del priorato de Rubillón, sufragáneo de Melón, ni los de Montecubeiro, foreros del convento de Santo Domingo de Lugo.

Para los monasterios resultaba rápido y sencillo ganar en la Audiencia del Reino una real provisión que les autorizaba a tomar posesión de bienes forales, una vez que mediante las escrituras originales acreditaba el directo dominio y la caducidad de las cesiones. Pero esto era solo un primer paso, necesario mas no siempre definitivo. A continuación un receptor del tribunal debía trasladarse a las parroquias en las que radicaban los bienes, identificarlos y ponerlos en manos de los monjes, y aquí era donde los colonos se hacían fuer-

26.AHN, Clero, cód. 60. 
tes, utilizando las armas propias de los débiles o la malicia campesina: la huida de los cabezas de casa para no declarar, avisados a menudo por el toque de campana que noticiaba de la presencia del receptor y la justicia local; la desmemoria, o la ignorancia invencible o -como ya dijera el gran Marc Bloch, la maravillosa facultad de olvidar-; las amenazas, a menudo obra de las mujeres casadas, sabedoras de que el derecho las trataba de frágiles y menores de edad, lo que les otorgaba cierta impunidad en las incidencias relacionadas con pleitos civiles; la recusación del relator por parcialidad o la reclamación de pagos de mejoras no contempladas en los foros originales ${ }^{27}$.

En aval de lo que queda señalado cabría exponer el desarrollo de varios pleitos ruidosos a los que hicieron frente monasterios y conventos, que no pudieron despojar a los colonos al ampararles el Consejo de Castilla con disposiciones ad casum, como la muy importante que dictó en marzo de 1762 para impedir que los bernardos de Sobrado convirtiesen en arrendatarios a más de cuatrocientos foreros de la parroquia de Portas, igual que le ocurrió al convento de Santo Domingo de Lugo con los vecinos del priorato de Montecubeiro, y a la postre también a monjes de Melón con los del priorato de Rubillón (Villares \& Díaz-Castroverde, 1997: 33-35). En este último caso las acciones conducentes al despojo se iniciaron en 1749 y afectaban a foros muy antiguos, varios de la década de 1570. Cuando los religiosos, con el apoyo de un receptor de su parcialidad, intentaron aplicar una ejecutoria de mayo de 1754 se encontraron con que los labradores del lugar de Penedo, instados por sus mujeres, se negaron a identificar los bienes en disputa y acabaron ausentándose: los vecinos del lugar de Penedo hicieron fuga y han extraído sus ganados, y se deja ver que sus operaciones son dirigidas a dejar ilusoria y sin efecto la ejecución de la real carta ejecutoria, acaba reconociendo el dependiente de la Real Audiencia ${ }^{28}$. Casi un año después de que el receptor llegara a Rubillón, los cabezas de casa de Penedo continuaban ilocalizables y el monje granjero exasperado, por no haber podido tomar posesión de las tierras:

tan lexos están de obedecer que se ausentaron [...] y dejaron en el mencionado lugar a las mujeres y familias [hijos], con orden expresa de que se hagan fuertes en él y prosigan en usar las casas y bienes como si no hubiera habido despojo, $y$ asi lo hacen, sin querer concurrir a recibir nuevo título, no obstante de que fixé cédulas en la puerta de la iglesia de esta feligresía, para que los que quisieren arrendar o aforar dicho lugar ocurriesen a mí, que les haría los correspondientes títulos.

27.Trata con ejemplos la cuestión Díaz-CASTROverde (1992, vOL. II); con carácter general ScotT (1985) y THOMPSON (1995).

28.ARG, Monasterios, leg. 88/15; y AHN, Clero, lib. 8.661. 
Por fin, en junio de 1755, receptor y juez ordinario, apoyados por algunos hombres contratados para la ocasión por el prior, expulsaron por la fuerza de sus casas a las mujeres y niños que las guardaran, en ausencia de sus maridos y padres, y sellaron las puertas con tablas clavadas ${ }^{29}$.

Pero las familias afectadas continuaron su lucha en la Real Audiencia, argumentando que quedaran reducidas a la condición de pobres que mendigaban de puerta en puerta. $\mathrm{El}$ regente envió al abad una carta en la que, bajo la forma de ruego cortés, le instaba a renovar los foros a los antiguos colonos, como así ocurrió en febrero de 1756. Los campesinos de Penedo usaron, por tanto, con habilidad su pobreza material y espiritual -ignorancia- como arma propia de los débiles, aunque para los monjes la malicia abundaba más que la pobreza, según advertía hacia 1700 el archivero de Oia: cuando litigan, escribe, los labradores llevan

unas alforxas al pescuezo, llenas de piedras lo de adelante; llegan a cualquier parte a ratear su pleito, $y$ todo es tirar piedras $y$ hacer $y$ decir maldades hasta que se acabe la alforxa.Y si por justicia o con razón (que será mucho) se les convence, vuelven la alforxa de atrás para delante y dicen: como somos pobres labradores y no sabemos leer ni escribir... Baptizan con nombre de sencillez lo que es pura malicia y falacia ${ }^{30}$.

La resolución de los conflictos que dieran origen al Expediente General de Foros es conocida: el Consejo de Castilla, después de varias medidas puntuales que anticipaban su posición final, por una provisión de 13 de mayo de 1763 ordenaba suspender la tramitación de las demandas (aunque prosiguieron algunos despojos autorizados por carta ejecutoria previa), y otra de 17 de diciembre de 1785 disponía que ni siquiera se admitiesen otras nuevas. Estas medidas eran en principio provisionales, en espera de una ley que iría al fondo del asunto, pero como no llegó, el foro se mantuvo desde entonces en una interinidad legal, en una situación en la que no era ni temporal ni perpetuo (Villares, 1989: 426).

Con independencia de las razones que llevaron al Consejo de Castilla a legislar en una determinada dirección y que quedaran mencionadas (fuerte resistencia de las comunidades rurales al despojo, escasa simpatía por el clero regular, orientación de la política agraria reformista), las provisiones de 1763 y 1785 convertían de hecho al foro en una enfiteu-

29.AHN, Clero, lib. 8.661; AHPO, Clero, lib. 400 de Melón, con los cuantiosos gastos judiciales de 1753 a 1778 , de compulsas, abogados, viajes y regalos.

30.AHN, Clero, cód. 60. 
sis perpetua y, por ello, reforzaban los derechos del útil frente al directo, una tendencia que se registra a lo largo de la Edad Moderna en muchos territorios, como ya advirtiera años atrás Bartolomé Clavero al tratar de la enfiteusis:

la idea de la temporalidad irá contrariamente oscureciéndose (...); la propia noción más singularizada de dominio de la tierra irá progresivamente basculando hacia la parte del enfiteuta, insinuándose una consideración de propiedad para el dominio inferior, más efectivamente relacionado con la tierra ${ }^{31}$.

\section{CONCLUSIÓN: EL RECURSO FINAL A LOS PRORRATEOS}

Los archivos monásticos, aun habiendo sufrido diversas pérdidas, acreditan el enorme esfuerzo que desde mediados del xvi llevaron a cabo los religiosos para controlar un patrimonio territorial cuya fisonomía cambiaba a menudo continua e intensamente. Tumbos, voluminosos apeos, libros de foros con índices detallados, memoriales cobradores, son el resultado del empeño por tener identificadas las parcelas, con su posesor y su renta. Por las razones que quedaron expuestas, los apeos fueron abandonados, pues para ser efectivos deberían actualizarse cada muy pocos años, para registrar la fragmentación y parcelación de las tierras. Para ir a la raíz del problema, los monjes intentaron convertir los foros en arriendos, con lo que los campesinos quedarían sin la capacidad que les daba la propiedad del útil para disponer de las haciendas que cultivaban, pero la resistencia de colonos, hidalgos y clérigos, apoyados por el Consejo de Castilla, frustró el proyecto.

Por ello, después de desistir tempranamente de la realización de apeos, y ver que los foros no sólo no se iban a convertir en arriendos, sino que de hecho perdían su carácter temporal, los monasterios, y no sólo ellos, recurrieron fundamentalmente a los prorrateos para garantizar la cobranza de las rentas, mediante la identificación de la tierra sobre la que pesaban y de su cultivador, que a la vez debía figurar en los minuciosos libros cobradores elaborados con carácter nominal. Puede decirse al respecto que si los años que van de 1550-1560 a 1650-1660 constituyen el siglo de los apeos, los de 1740-1750 a la exclaustración lo son de los prorrateos ${ }^{32}$.

31.Clavero (1986: 482); también Villares (1988). Sobre el fortalecimiento de la propiedad útil en diversos territorios europeos hay abundantes pruebas en THOMPSON (1995) y CoNGOST (2007).

32.Así, en el caso de San Martín Pinario, los 20 prorrateos conservados en el Archivo de la Universidad de Santiago y en el de San Paio de Antealtares son todos de la segunda mitad del xviII y principios del XIX. 
Los prorrateos eran operaciones caras, y a menudo conflictivas, pero los monasterios procuraban, no siempre con éxito, obligar a los colonos a efectuarlas periódicamente a su costa, y éstos o una parte de ellos podían estar interesados en la realización, para evitar pagar más renta de la que les correspondía. Así, el padre panero de Xunqueira de Espadañedo, en una comarca en que predominaban la herencia igualitaria, advertía en 1788 a sus sucesores: por cuanto los colonos de esta jurisdicción están continuamente rateando los forales, tendrá presente el padre panero que fuese que luego que le presenten algún rateo nuevo, verá si lo traen arreglado y si no lo traen arreglado lo devolverá hasta que se lo completen. Lógicamente, los prorrateos actualizados y los libros cobradores debían concordar, pues no bastaba con cobrar la renta, sino que era preciso saber a qué foro correspondía para evitar confusiones y con el tiempo impagos:

de no haberlo hecho asi [sus antecesores] dieron lugar de quitar [renta] de un foro y añadir en otro, por no saber los herederos o compradores explicar a qué foro pertenecían las tierras, pareciéndoles [a los padres paneros] que importa poco se ponga la renta en este o en otro foro, con tal que el monasterio cobre la renta [...], sin advertir que de este modo llegará tiempo de que no haya foro con foro en el memorial ${ }^{33}$.

Aparte de los costos y conflictos que generaban, los prorrateos pronto envejecían y, como sucedía con los apeos, la circulación de la tierra obligaba a actualizarlos cada poco tiempo. Así, en 1720 los poseedores de los bienes de la granja de Cela, de Melón, nombraron a dos peritos tasadores para efectuar un prorrateo, y no bien acabado el trabajo tuvieron que volver a inspeccionar y reconocer, medir y valuar todos los recintos y piezas que cada uno de ellos posee, porque en poco tiempo hubiera permutas y enajenaciones entre diversos sujetos $[\mathrm{y}]$ hasta también algunas divisiones entre herederos ${ }^{34}$. Por su parte el monasterio de Sobrado acometió en 1779-1787 la realización del prorrateo de tres casales (en origen explotaciones), aforados en $1649 \mathrm{y}$ sitos en el priorato de Toxosoutos. Al solicitar la autorización a la Real Audiencia los monjes argumentan que varios foreros no pagan la renta por entero, motivado de haberse propasado muchos de los enfiteutas a vender, permutar y enajenar diversas partidas de bienes, dándolos por libres y sin carga de dominio, quedándose ellos recargados de la renta, y otros a hacer partixas y divisiones entre labradores, todo lo cual daba origen a atrasos en los pagos y al oscurecimiento del dominio. Pero la operación fue complicada y muy conflictiva, porque desde la fecha de los foros originales se había multiplicado el número de colonos, se roturaron tierras y no

33.AHPO, Clero, lib. 459. Sobre el contenido de los prorrateos, véase ViLLARES (1982: 70-73).

34.AHPO, Clero, caja 9.923. 
resultaba fácil deslindar las correspondientes a diversos forales. El pleito acabó en la Chancillería de Valladolid, y ocupa más de dos mil hojas ${ }^{35}$.

En fin, en los libros de gastos en pleitos y en los abadologios menudean desde doblado el siglo XVIII las referencias a prorrateos. El de Oseira menciona los rateos como causantes de desembolsos judiciales de modo regular desde el cuatrienio 1771-1775: se executan prorrateos, se hicieron varios prorrateos, se prosiguió en los prorrateos, muchos rateos se hicieron en varios prioratos, o, ya en 1824-1828, se rateó la granxa de Munitás y que fue muy costoso por la fuerte oposición que hubo de parte de los poseedores. El libro de pleitos de la comunidad acredita las dificultades de diversas operaciones: entre abril de 1775 y abril de 1777, por ejemplo, el archivero pasa cuatro meses en Lalín, acompañando a un receptor que cobra 5.975 reales, a los que se añaden 1.276,75 de regalos. En la década de 1780 se ratean forales en Dozón y Oleiros, y en Ribadavia, en donde la acción supone conflictos con los dominicos de la villa y con el conde y origina un gasto de 6.607,25 reales. en el ejercicio 1781-1782. Algunos de estos conflictos continúan en la década siguiente, cuando el monasterio ha de efectuar más prorrateos, entre ellos los del priorato de Marín, que se prolongaron años (6.642,5 reales desenvolsados en 1792-1795 y 6.054 en $1798-1799)^{36}$.

Pero fueron bastante más graves las dificultades y gastos que afrontó en algunas administraciones el monasterio de Melón. Pese a la fuerte oposición, en 1774 inició el rateo del priorato de A Xironda: el ejecutor ocupó 142 días y el escribiente 197, percibiendo entre ambos 5.986,5 reales; las operaciones prosiguieron en los años siguientes: en 17761777 el primero trabaja 190 días y el segundo 364, y devengan unos 9.000 reales., y en 1777-1778 aún continúan, durante 147 jornadas, las tareas del ejecutor. Cuando los religiosos llevaban concluida tan costosa y laboriosa obra, para la que habían tenido que compulsar muchos foros, los colonos reaccionaron presentando en el Real Consejo una demanda de incorporación a la corona, lo que más adelante dio origen al impago completo de rentas forales. En otros prioratos el monasterio tuvo que vencer también resistencias para llevar a término prorrateos: en San Adrián en 1778-1779, porque había un foral en que los cabezaleros no podían ajustar la renta contenida en él, porque algunos de los poseedores llevaban bienes sin pagar nada; en la granja de Outeiro en 1785-1786 y 17891790; en la de Reza en 1794-1795 y 1798-1799; en Lougares y Moucende en 1798-1799; en la de Turóns en 1800-1801 (son necesarios 49 días para citar a todos los colonos y no

35.Archivo Real Chancillería de Valladolid, cajas 3.416/1 y 3.418/1.

36.AHPO, Clero, lib. 607 de Oseira, con mucha más información sobre gastos judiciales. En el caso de Monfero, la mayor parte de las salidas monetarias por razón de pleitos de la década de 1780 está también motivada por prorrateos. AHN, Clero, lib. 3.047. 
se finalizan los trabajos hasta 1803/04); en Guillade en 1803-1804, después de que la oposición de los vecinos obligase al monasterio a sacar una real provisión ${ }^{37}$.

Día a día, los monjes encargados de la cobranza de rentas, en especial los destacados en los prioratos, y del archivo debían luchar sin descanso contra la llamada -por ellosmalicia campesina, y si damos crédito a sus quejas reiteradas sobre pérdidas de hacienda y de ingresos habría que concluir que su esfuerzo tuvo escaso éxito. Pero las contabilidades prueban que los monasterios llegaron a la exclaustración de 1835 percibiendo sin mayores problemas, salvo en unas pocas administraciones, las rentas forales al completo y también los diezmos mayores (Rionegro, 1998; Seijas, 2009). Incluso después del Trienio los libros de panera, bodega, caja y prioratos reflejan una normalidad asombrosa.Y es que, aunque parezca una paradoja -cuya explicación exigiría bastantes páginas-, en la Galicia del Antiguo Régimen el poder de las instituciones y familias rentistas no estuvo reñido con la fortaleza del campesinado que las sostenía mediante el pago de foros y diezmos. La escasa jerarquización de las comunidades vecinales y su control cada vez más efectivo del usufructo de la tierra -incluidos los dilatados espacios comunales- explican en buena medida la sólida posición de los foreros, y las «epopeyas» protagonizadas por aldeas y parroquias, sosteniendo pleitos ruidosos, estuvieron más orientadas a asegurarse la iniciativa en el aprovechamiento del labradío y monte que a librarse de la totalidad de las rentas que pagaban en contrapartida.

A la vez, los rentistas, y en el caso que nos ocupa los monasterios, se beneficiaron de la expansión demográfica y agraria del XVI-XVII, pero como su economía se basaba en ingresos en especie en su mayor parte difíciles de modificar a corto plazo su situación financiera venía determinada a la postre por la fluctuación de unos precios que tampoco controlaban. Con todo, en la etapa final del Antiguo Régimen, por circunstancias políticas y sociales, atravesaron una situación mucho menos grave que los monasterios y conventos del centro y sur peninsular: no les afectó la primera y desastrosa exclaustración de 1809 , ni los estragos en inmuebles, cosechas y ganados que sufrieron los regulares que explotaban directamente una parte significativa del patrimonio (López Martínez, 1992: 287-320); tampoco debieron hacer frente a una oposición significativa del campesinado y de otros sectores sociales. De hecho, durante la guerra de la Independencia muchos monjes de Castilla y León se refugiaron en prioratos y abadías de Galicia, y no por casualidad los capítulos generales de benitos y bernardos de 1815 y 1816 se celebraron en Celanova y Oseira, porque San Benito de Valladolid y Palazuelos se encontraban a la sazón en estado ruinoso.

37.AHPO, Clero, Melón, lib. 400.

Historia Agraria, 74 - Abril 2018 • pp. 7-36 
Claro que ésta es una parte de la historia económica de las comunidades monásticas: la que se refiere a la cobranza de las rentas en especie. La otra, menos optimista y de la que ahora solo toca advertir, viene constituida por su situación financiera o balances de ingresos y gastos monetarios, deteriorados desde comienzos del XIX en buena medida por causas de tipo político-fiscal: la reforma beneficial, que obligaba a elevar las congruas de los vicarios que atendían parroquias de patronato y que amparados en la nueva legislación inician pleitos costosos para los monjes; la supresión de diezmos exentos, que desde 1803, junto con el real noveno, pasan a ser cobrados por el Crédito Público; los donativos y contribuciones, gravosas desde 1809 a 1820 , y a partir de 1818 la caída brutal de los precios de venta de cereales y vino, constituyen los principales factores que, sumados unos a otros, inciden de modo negativo en las finanzas de los monasterios, pero no hasta el extremo de que en vísperas de la exclaustración quepa calificar su estado de ruinoso (Rey, 1991: 288-303; Rionegro, 1998).

\section{AGRADECIMIENTOS}

El autor agradece a los cinco evaluadores anónimos de esta revista su detenida lectura del texto y las sugerencias que le formularon para mejorarlo.

Este trabajo fue realizado en el marco del proyecto de investigación HAR201452667-R, financiado por el Ministerio de Economía y Competitividad.

\section{REFERENCIAS}

Antoine, A. (2001). Le paysage de l'historien: Archèologie des bocages de l'Ouest de la France á l'époque moderne. Rennes: Presses Universitaires de Rennes.

BARReiro MALlón, B. (1972). La Pragmática de perpetuación de foros: Intento de interpretación. Compostellanum, (XVII), 73-116.

BEAUROY, J. (2002). La représentation de la propriété privée de la terre: Land surveyors et estate maps en Angleterre de 1570 à 1660. En G. BRunEL, O. GuYOTJEANNIN \& J.M. MORICEAU (Eds.), Terriers et plans terriers du XIII au XVIII siècle (pp. 79-101). Paris: École Nationale de Chartres.

Bendall, S. (2010). Maps, Land and Society: A History, with a Carto-Bibliography, of Cambridgeshire Estate Maps. Cambridge: Cambridge University Press.

BLoch, M. (1929). Les plans parcellaires. Annales d'histoire économique et sociale, (1), 6070. 
Brunel, G., Guyotjeannin, O. \& Moriceau, J. M. (Eds.) (2002). Terriers et plans terriers du XIII au XVIII siècle. Paris: École Nationale de Chartres.

CAmarero, C. (1998). La cartografía en el catastro de Ensenada, 1750-1756. Estudios Geográficos, 59 (231), 245-283.

Clavero, B. (1986). Enfiteusis, ¿qué hay en un nombre? Anuario de Historia del Derecho Español, (56), 467-519.

Congost, R. (2007). Tierras, leyes, historia: Estudios sobre «la gran obra de la propiedad». Barcelona: Crítica.

Congost, R., Jover, G. \& BiAgioli, G. (Eds.) (2003). L'organització de l'espai rural a l'Europa mediterrània: Masos, possessions, poderi. Girona: CCG.

Díaz-Castroverde, J. L. (1992). Conflictividad social y régimen de propiedad en Galicia: La cuestión de los despojos. Tesis doctoral inédita. 2 vols. Universidade de Santiago de Compostela.

Díaz-Castroverde, J. L. (1995). Conflictos por la tierra en la provincia de Orense durante el siglo XviII. En J. De Juana \& X. CASTRo (Eds.), AnexoVIII Xornadas de Historia de Galicia (pp.133-151). Ourense: Deputación Provincial de Ourense.

FERnÁNDEZ GonZÁleZ, A. I. (1995). Los grupos de poder local en Galicia, 1750-1850. Noticiario de Historia Agraria, 5 (9), 129-153.

FERNÁNDEZ GonzÁLEZ, A. I. (1998). A Igrexa como institución rendista ó longo do Antigo Réxime. En G. PEREIRA (Coord.), Galicia fai dous mil anos: O feito diferencial galego. I: Historia (pp. 37-73). Santiago de Compostela: Museo do Pobo Galego.

Ferro, J. (1980). Catálogo de libros de la sección de Clero:Archivo Histórico Provincial de Orense. Madrid: Ministerio de Cultura.

Gallego, O. (1991). El archivo del monasterio de Celanova. Madrid: Dirección de Archivos Estatales.

GARCÍA SANZ, A. (1996). La reforma agraria de la Ilustración: Proyectos y resultados. El precedente del arbitrismo agrarista castellano. En A. GARCía SANZ \& J. SANZ FERNÁNDEZ (Eds.), Reformas y políticas agrarias en la historia de España (pp.161-200). Madrid: Ministerio de Agricultura, Pesca y Alimentación.

GRUPO'75 (1977). La economía del Antiguo Régimen: La «renta nacional» de la Corona de Castilla. Madrid: Universidad Autónoma de Madrid.

López Martínez, A. L. (1992). La economía de las órdenes religiosas en el Antiguo Régimen: Sus propiedades y rentas en el reino de Sevilla. Sevilla: Diputación Provincial de Sevilla.

Lucas, M. (1999). El archivo del monasterio de San Martiño de Fóra o Pinario de Santiago de Compostela. Sada: Ediciós do Castro.

LunA, P. (2005). El intocable dominio y las reformas de la posesión: Los planteamientos de Campomanes. Tiempos modernos, 4 (12), 1-26.

Martín, E. (1953). Los Bernardos españoles (Historia de la Congregación de Castilla de 
la Orden del Císter). Palencia: Gráficas Aguado.

McRAe, A. (2002). God Speed the Plough:The Representation of Agrarian England, 15001660. Cambridge: Cambridge University Press.

Pérez García, J. M. (1979). Un modelo de sociedad rural de Antiguo Régimen en la Galicia costera. Santiago de Compostela: Universidade de Santiago de Compostela.

Portela, M. J., Garrido, M. \& Romaní, M. (1993). Repertorio para las escrituras antiguas del Archivo Bajo: Catálogo del Archivo Monacal de Oseira en 1629. Santiago de Compostela: Tórculo.

Quiroga, G. (1986). Organización de un fondo monacal: El monasterio de Santa María de Montederramo. Boletín Auriense, (16), 183-235.

Quiroga, G. (1999). Real Audiencia de Galicia: Catálogo de expedientes de apeo. Santiago de Compostela: Xunta de Galicia.

Quiroga, G. (2007). Real Audiencia de Galicia: Catálogo de preitos e expedientes de mosteiros. 3 vols. Santiago de Compostela: Xunta de Galicia.

Rey, O. (1991). La crisis de la economía de las instituciones eclesiásticas de Galicia. En P. SAavedra \& R. Villares (Eds.), Señores y campesinos en la Península Ibérica, siglos XVIII-XX. I: Os señores da terra (pp. 261-303). Barcelona: Crítica.

ReY, O. (1992). El reparto social del diezmo en Galicia. Obradoiro de Historia Moderna, (1), 145-162

Rionegro, I. (1998). La estructura económica del Císter orensano en la fase final del Antiguo Régimen. Ourense: Caja de Ahorros Provincial de Orense.

SAAVEDRA, P. (1985). Economía, política y sociedad en Galicia: La provincia de Mondoñedo, 1480-1830. Santiago de Compostela: Xunta de Galicia.

SAAVEDRA, P. (1990). Contribución al estudio del régimen señorial gallego. Anuario de Historia del Derecho Español, (60), 103-184.

SAAVEDRA, P. (2007). Reforma fiscal y control del territorio: El catastro de Ensenada -o «confusión de Babel»- en Galicia. Anuario de historia del Derecho Español, (77), 771884.

SAavedra, P. (2013). Demarcacións, topónimos, papeis, memoria: Sobre a división e control do territorio na Galicia Moderna. A Coruña: Real Academia Galega.

Scott, J. C. (1985). Weapons of the Weak: Everyday Forms of Peasant Resistence. New Haven: Yale University Press.

Seijas, M. (2010). Los cistercienses en el sudoeste de Galicia a fines del Antiguo Régimen. Tesis doctoral: Universidade de Santiago de Compostela. https://minerva.usc.es/xmlui/ bistream/1034/2675_content.pdf

SERENI, E. (1961). Storia del paesaggio agrario italiano. Roma: Laterza.

SuÁREZ GonZÁLEZ, A. (2016). Memoria renovada a fines del quinientos: El tumbo partido de Santa María de Sobrado. En A. Marchant \& L. C. Barco (Coords.), «Dicebamus hesterna die....Estudios en homenaje a los profesores Pedro f. Arroyal Espiga- 
res y $M^{a}$ Teresa Martín Palma» (pp. 512-537). Málaga: Universidad de Málaga. Thompson, E. P. (1995). Costumbres en común. Barcelona: Crítica.

Tos I URgellés, J. (2007 [1784]). Tratado de la cabrevación. Edición y estudio introductorio de Rosa Congost. Girona: Associació d'Història Rural de les Comarques Girondines.

TouZery, M. (Ed.) (2007). De l'estime au cadastre en Europe: L'époque moderne. Paris: Comité pour l'histoire économique et financière de la France.

VILLARES, R. (1982). La propiedad de la tierra en Galicia. Madrid: Siglo XXI.

VILLARES, R. (1988). Los foros de Galicia: algunos problemas y comparaciones (Galicia, Portugal, Valencia). Ler Historia, (12), 47-75.

VILLARES, R. (1989). Carlos III y la temporalidad del foro: Los pleitos sobre despojos. En Estructuras agrarias y reformismo ilustrado en la España del siglo XVIII (pp.411-428). Madrid: Ministerio de Agricultura, Pesca y Alimentación.

Villares, R. (1997). A provisión de 1763 revisitada. En O padre Sarmiento e o seu tempo (pp. 209-224). Santiago de Compostela: Consello da Cultura Galega/Universidade de Santiago de Compostela.

VILlares, R. \& Díaz-CASTROVERDE, J. L. (1997). O conflicto foral nos séculos XVII e XVIII. Ourense: Xunta de Galicia/Caixa Ourense. 